\title{
Distribution level SiC FACTS devices with reduced DC bus capacitance for improved load capability and solar integration
}

\author{
Peter Wolfs \\ Power and Energy Centre \\ Central Queensland University \\ Rockhampton, Australia \\ p.wolfs@cqu.edu.au
}

\author{
Fuwen Yang, Qing-Long Han \\ Centre for Intelligent and Networked Systems \\ Central Queensland University \\ Rockhampton, Australia \\ f.yang@cqu.edu.au, q.han@cqu.edu.au
}

\begin{abstract}
FACTS devices, such as STATCOMs and UPFCs can be directly applied in the low voltage distribution system to regulate the sequence voltages within a network while simultaneously cancelling zero and negative sequence currents that are introduced by load unbalance or by high levels of distributed photovoltaic generation. Instantaneous reactive power theory shows that for FACTS devices the DC-bus capacitor power will fluctuate at twice mains frequency during unbalanced operation. High rating non-polarized bus capacitors can be applied if the double frequency fluctuations are restricted. In combination with silicon carbide devices it becomes possible to produce compact pole mounted systems. This paper proposes control methods that allow distribution level or dFACTS compensators with finite rating to best allocate its capacity to voltage, current balancing and reactive power compensation.
\end{abstract}

Keywords - FACTS, power quality, photovoltaisc, distributed generation; instantaneous power theory, reduced bus capacitance.

\section{INTRODUCTION}

The global base of installed PV surpassed 100GW in 2012 [1] and much of that capacity is installed in roof-top residential systems. Significant power quality issues, especially voltage rise and voltage unbalance have been widely studied, [2-4]. The penetration of renewable energy supply into distribution networks is materially restricted by the voltage management philosophies that were applied when networks where constructed. Higher penetrations or renewable generation within the distribution network can be achieved by the addition of intelligent control, storage or regulatory devices, [5-6].

Flexible AC transmission system, (FACTS) technology, while developed for the transmission network can be applied at the distribution level and is referred to as dFACTS technology. Fig. 1 shows a distribution level shunt device based on a static compensator, (dSTATCOM), [7], and Fig. 2 shows a series device based on a distribution level unified power flow controller, (dUPFC), [8]. For LV four-wire threephase distribution networks as found in Europe and Australia, full current and voltage compensation schemes require three degrees of freedom. Either four-leg converters or three single phase inverters with a coordinating control can be applied. The dSTATCOM has a direct capability to rebalance currents and to undertake reactive power compensation. It can indirectly control voltage through reactive power injections. The dUPFC styled device has a direct capability to inject a series voltage and to undertake voltage regulation. The shunt converter supplies the necessary real power for voltage regulation. If the shunt element is adequately rated it can undertake further dSTATCOM operations.

For distribution applications pole top mounted equipment is economically attractive. Silicon-carbide power electronic devices offer lower losses and tolerance for higher operating temperatures, [9]. Electrolytic capacitors often determine the limitations on working temperature for converters and can contribute significantly to cost and failure rate, [10-11]. Fig. 3 shows a current example of a compact $\mathrm{SiC}$ inverter for dSTATCOM applications. This paper explores how these dFACTS devices can be controlled if the DC bus capacitor size is reduced by two orders of magnitude - a one hundred fold reduction. CDE, and others now provide high-current polypropylene capacitors for inverter applications, [12]. As electrolytic capacitors with tens of thousands of microfarads are replaced by polypropylene capacitors of hundreds of microfarads the major research challenge is to manage the DC capacitor voltage by ensuring instantaneous power balance for the converter [13].

\section{DC CAPACITOR VOLTAGE VARIATION AND INSTANTANEOUS POWER FLOW}

A converter within a voltage regulation or current compensation system will transfer instantaneous power that has continuous and fluctuating components. For example, consider the four-leg converter shown in Fig.1. The instantaneous power developed by the converter is, [7]:

$$
\begin{aligned}
p_{c}(t) & =i_{a p}(t) \times v_{a n}(t)+i_{b p}(t) \times v_{b n}(t)+i_{c p}(t) \times v_{c n}(t) \\
& =\overline{p_{c}}+\tilde{p_{c}}
\end{aligned}
$$

The instantaneous power has as an average value, $\bar{p}$, and an oscillatory component $\tilde{p}$. The voltage at the point of common coupling (PCC) is expressed as a sum of positive, negative and zero sequence components:

$$
v_{a n}(t)=\sqrt{2} V_{+} \sin \left(\omega t+\varphi_{v_{+}}\right)+\sqrt{2} V_{-} \sin \left(\omega t+\varphi_{v_{-}}\right)
$$




$$
\begin{gathered}
+\sqrt{2} V_{0} \sin \left(\omega t+\varphi_{v 0}\right) \\
v_{b n}(t)=\sqrt{2} V_{+} \sin \left(\omega t-2 \pi / 3+\varphi_{v+}\right)+ \\
\sqrt{2} V_{-} \sin \left(\omega t+2 \pi / 3+\varphi_{v-}\right)+\sqrt{2} V_{0} \sin \left(\omega t+\varphi_{v 0}\right) \\
v_{c n}(t)=\sqrt{2} V_{+} \sin \left(\omega t+2 \pi / 3+\varphi_{v+}\right)+ \\
\sqrt{2} V_{-} \sin \left(\omega t-2 \pi / 3+\varphi_{v-}\right)+\sqrt{2} V_{0} \sin \left(\omega t+\varphi_{v 0}\right)
\end{gathered}
$$

Similarly the compensation currents can be expressed as:

$$
\begin{array}{r}
i_{a p}(t)=\sqrt{2} I_{p+} \sin \left(\omega t+\varphi_{i p+}\right)+\sqrt{2} I_{p-} \sin \left(\omega t+\varphi_{i p-}\right) \\
+\sqrt{2} I_{p 0} \sin \left(\omega t+\varphi_{i p 0}\right) \\
i_{b p}(t)=\sqrt{2} I_{p+} \sin \left(\omega t-2 \pi / 3+\varphi_{i p+}\right)+ \\
\sqrt{2} I_{p-} \sin \left(\omega t+2 \pi / 3+\varphi_{i p-}\right)+\sqrt{2} I_{p 0} \sin \left(\omega t+\varphi_{i p 0}\right) \\
i_{c p}(t)=\sqrt{2} I_{p+} \sin \left(\omega t+2 \pi / 3+\varphi_{i p+}\right)+ \\
\sqrt{2} I_{p-} \sin \left(\omega t-2 \pi / 3+\varphi_{i p-}\right)+\sqrt{2} I_{p 0} \sin \left(\omega t+\varphi_{i p 0}\right)
\end{array}
$$

The resulting average and oscillatory powers can be found, using reference [14] equations 3.76 and 3.81, as:

$$
\begin{aligned}
\overline{p_{c}}= & 3 V_{+} I_{p+} \cos \left(\varphi_{v+}-\varphi_{i p+}\right)+ \\
& 3 V_{-} I_{p-} \cos \left(\varphi_{v-}-\varphi_{i p-}\right)+ \\
& 3 V_{0} I_{p 0} \cos \left(\varphi_{v 0}-\varphi_{i p 0}\right) \\
\bar{p}_{c}= & -3 V_{+} I_{p-} \cos \left(2 \omega t+\varphi_{v+}+\varphi_{i p-}\right)- \\
& 3 V_{-} I_{p+} \cos \left(2 \omega t+\varphi_{v-}+\varphi_{i+}\right)- \\
& 3 V_{0} I_{p 0} \cos \left(2 \omega t+\varphi_{v 0}+\varphi_{i p 0}\right)
\end{aligned}
$$

In practical applications the shunt converter input voltage has a dominant positive sequence component, $V_{p+} \angle \varphi_{v p+}$, but is not necessarily completely balanced. However if

$$
V_{+} \gg V_{-}
$$

Then

$$
\begin{aligned}
& \overline{p_{c}} \approx 3 V_{+} I_{p+} \cos \left(\varphi_{v+}-\varphi_{i p+}\right) \\
& \tilde{p_{c}} \approx-3 V_{+} I_{p-} \cos \left(2 \omega t+\varphi_{v+}+\varphi_{i p-}\right)
\end{aligned}
$$

If the DC bus must carry the oscillatory power given by (12) then the energy storage is the area under one half cycle of the cosine waveform. The required capacitor size depends upon the upper and lower DC bus voltage limits, $\mathrm{V}_{\mathrm{H}}$ and $\mathrm{V}_{\mathrm{L}}$, and is given by:

$$
C=\frac{6 V_{+} I_{p-}}{\pi f\left(V_{H}^{2}-V_{L}^{2}\right)}
$$

\section{IMPLICATIONS FOR DSTATCOM CONTROL}

For dSTATCOM devices, unbalanced operations give rise to DC bus voltage fluctuations. Similar conditions apply to a dUPFC. Equation 13 shows an inverse square relationship between bus voltage and the DC capacitance value. As SiC devices have inherently higher voltage ratings, the capacitor size can be practically reduced by allowing operations with higher DC bus voltages. In order to ensure the safe operation of the equipment, fast responding DC bus voltage management systems are required.

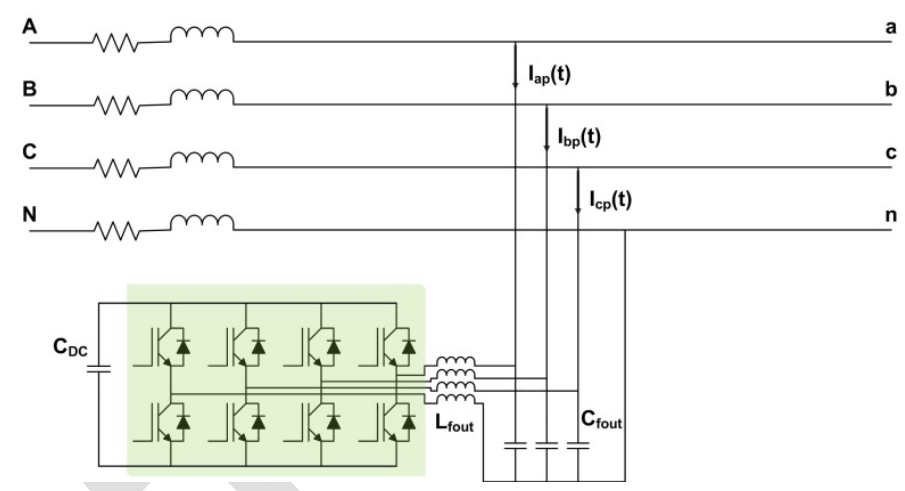

Fig. 1. dSTATCOM with Reduced DC Bus Capacitor, [7].

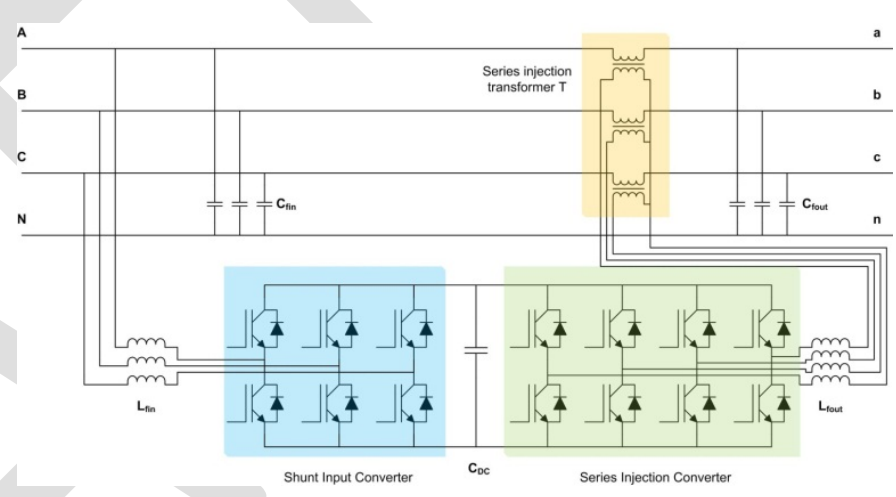

Fig. 2. UPFC with Reduced DC Bus Capacitor, [8].

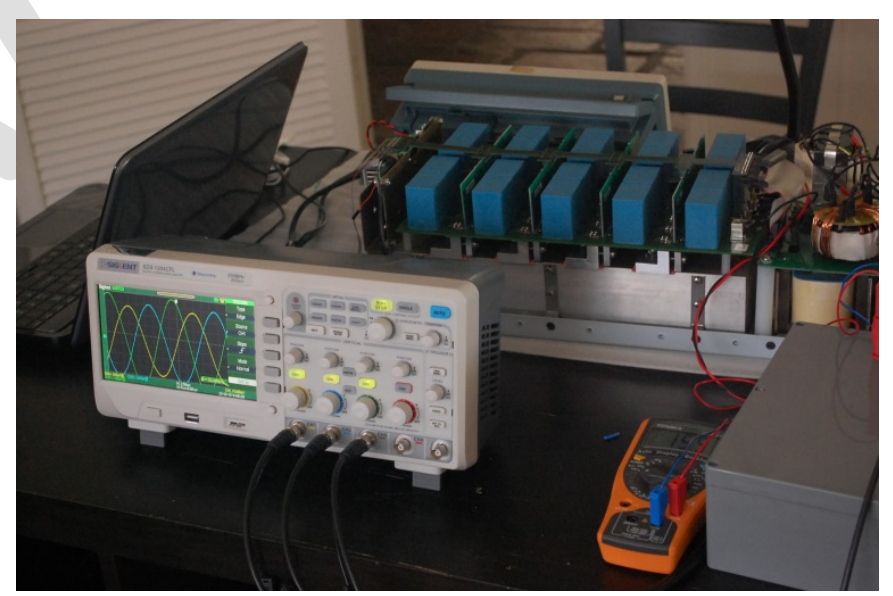

Fig. 3. A 30kVA SiC dSTATCOM prototype with polyproplyene DC bus capacitors, Image courtesy of Elevare Energy

An instantaneous power control system could be constructed in an $\alpha, \beta$ frame, [14], but this paper proposes a positive and negative sequence framework approach. The sequence based controls are implemented in dq reference frames and the sine cosine reference waveforms are recovered from the local converter input voltages using a phased locked loop (PLL), $[14,15]$. 
The FACTS converters contain several shared control features especially with regard to the DC bus capacitor control. Fig. 4, a dSTATCOM control developed for the converter shown in Fig. 3, illustrates that the capacitor control system has two parts:

- A DC capacitor average voltage control loop that responds to errors in the average DC bus voltage. The controller $\mathrm{G}_{\mathrm{cdc}}(\mathrm{s})$ has a PI response;

- An instantaneous DC bus voltage limit function. The controller $\mathrm{G}_{\text {cinst }}(\mathrm{s})$ could have a proportional or hysteresis response. During transients this controller may demand short bursts of positive sequence current that persist for a few milliseconds.

In a dSTATCOM with limited DC bus capacitance and phase leg current limit it is possible to strategically allocate the available capability. A reasonable priority allocation is to:

- Compensate negative sequence currents;

- Compensate zero sequence currents;

- Correct positive sequence reactive power flows.

The limitations on the compensator current are the phase leg current rating $\left(\mathrm{I}_{\mathrm{L}}\right)$ and the DC bus voltage ripple limits. The negative sequence current compensation gives rise to DC bus voltage ripple. The negative sequence current, and the consequent peak to peak bus voltage ripple, is limited by a vector length constraint as shown in Fig. 4. The vector limitation should be applied so that the $\mathrm{dq}$ vector phase angle is maintained.

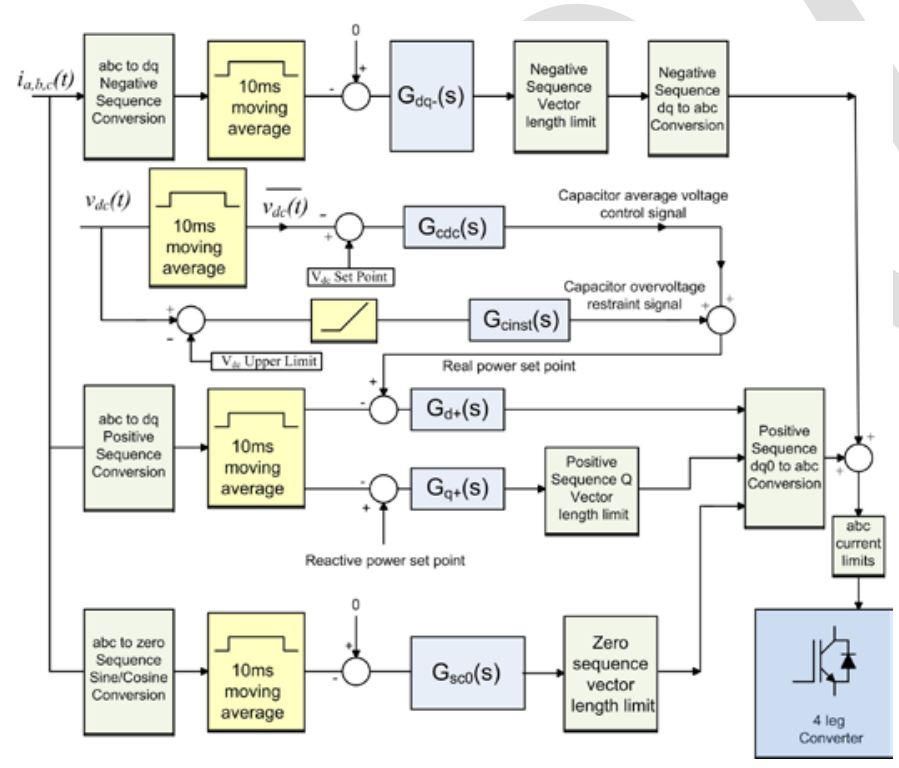

Fig. 4. Sequence based dSTATCOM control strategy.

The zero sequence compensation is performed using a sine-cosine transformation that reduces the zero sequence currents to DC terms. PI regulators determine the appropriate compensation vector. The zero sequence vector is subject to a magnitude constraint and this strongly affects the current in the neutral connected compensator leg. It is useful to set the zero sequence limit to one-third of $\mathrm{I}_{\mathrm{L}}$ as the current is the neutral connected leg is three times this limit or $\mathrm{I}_{\mathrm{L}}$. If all four phase legs are designed for $\mathrm{I}_{\mathrm{L}}$ the compensator will be able to simultaneously provide a negative sequence current of twothirds $I_{L}$ with a zero sequence current of one-third $I_{L}$ without any leg current limit being exceeded.

Depending on the dSTATCOM ratings, and the relative phase angles of the sequence components, substantial positive sequence compensation may be additionally available. In Fig. 4 the negative sequence limit is fixed but the zero and positive sequence limits are dynamically imposed to ensure that the dSTATCOM capability is allocated according to the established priorities.

\section{IMPLICATIONS FOR DUPFC CONTROL}

This paper assumes the series element of the dUPFC is voltage controlled and utilized for voltage regulation of the output terminals. A suitable control for the parallel element of a dUPFC is shown in Fig. 5. Two types of operation are possible:

- A voltage regulator focused action termed dUPFClight;

- A regulator and parallel compensation action termed dUPFC-heavy.

For dUPFC-light operations the primary action is to regulate the output voltage magnitude and voltage phase balance using the series element to inject unbalanced voltages. The shunt converter simply provides the instantaneous compensation power. It is possible to actively cancel the power fluctuations on the DC bus.

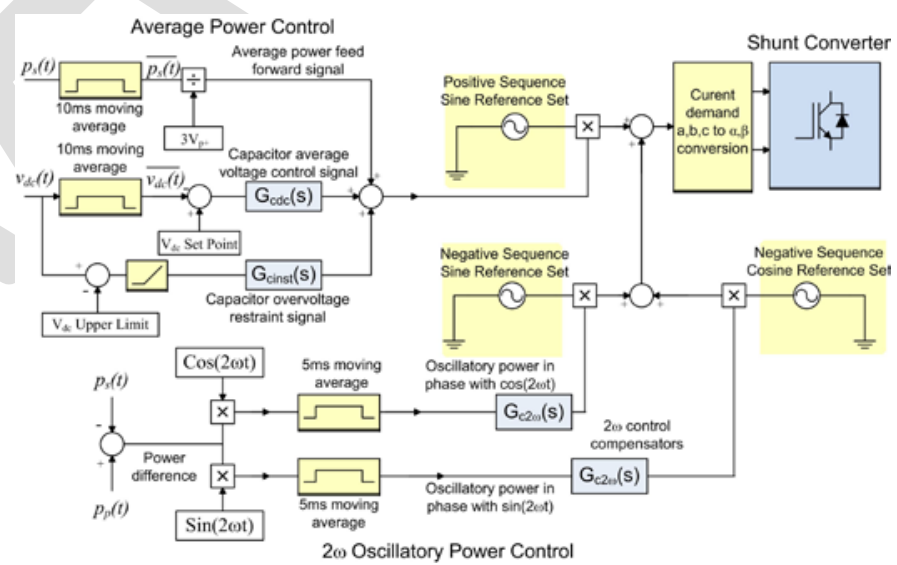

Fig. 5. Power Control for a dUPFC Parallel Element.

The series converter instantaneous power, $p_{s}(t)$, in Fig. 5, produces a $2 \omega$ power fluctuation at the DC bus. The parallel converter power, $p_{p}(t)$, can be controlled to force the resultant DC bus capacitor power fluctuation to zero. This is achieved by controlling the shunt converter to draw an appropriate negative sequence current. Inspection of (5) to (7) and (8) shows a sine negative sequence current produces a $\cos (2 \omega t)$ power fluctuation. In Fig. 5, the $\cos (2 \omega t)$ power varitation is synchronously detected by multiplying the sereis and shunt converter power difference by $\cos (2 \omega \mathrm{t})$ and then low pass filtering with a $5 \mathrm{~ms}$ moving average filter. The resulting power term drives a PI compensator that adjusts the a sine 
negative sequence current reference to force the power variation to zero. Trigonometric relationships can be applied to (5) to (7) and (8) to show that $\sin (2 \omega t)$ power fluctuations can be cancelled using a cosine negative sequence current. It is possible to internalize the $2 \omega$ power fluctuation to the DC capacitor or pass the fluctuation through the shunt converter which then must draw a negative sequence current. This becomes a design choice.

For dUPFC-heavy applications the shunt converter has a dual duty. It provides the real power requirements of the series converter and undertakes a full range of dSTATCOM roles. The shunt converter may be implemented with three phase legs for positive and negative sequence compensation duty or with four phase legs if zero sequence compensation is required for a four-wire system.

\section{Continuous Time Model Simulation Results}

Fig.6 shows a FACTS voltage compensator placed at the far end of a $300 \mathrm{~m}$ low voltage four-wire three-phase aerial feeder constructed with a $7 / 3.75 \mathrm{~mm}$ all-aluminum conductor (AAC). The performance of the dSTATCOM and a UPFClight will be compared in this instance. The conductor impedance is $(0.452+0.270 \mathrm{j}) \Omega / \mathrm{km}$. The supply transformer is rated at $200 \mathrm{kVA}, 415 / 240 \mathrm{~V}, 50 \mathrm{~Hz}$ and has a per-unit series impedance of $0.01+0.03 \mathrm{j} \Omega$. Three $100 \mathrm{~A}_{\mathrm{rms}} 0.95 \mathrm{pf}$ lagging loads are applied to the far end of the feeder. A switchable $95 A_{\text {rms }}$ unity power factor single-phase solar generator, which fully compensates the real power requirement of the phase " $b$ " load, is also placed at the far end and is connected to phase " $b$ ". The key simulation parameters for the dSTATCOM and UPFC-light are shown in Table 1.

TABLE 1. SIMULATION PARAMETERS

\begin{tabular}{|c|c|c|}
\hline Parameter & dSTATCOM & dUPFC-light \\
\hline Nominal converter rating & $75 \mathrm{kVA}$ & $6 \mathrm{kVA}$ \\
DC capacitor & $690 \mu \mathrm{F} ;$ & $10 \mu \mathrm{F} ;$ \\
$\mathrm{V}_{\mathrm{dc}}$ Set Point & $750 \mathrm{~V} ;$ & $700 \mathrm{~V} ;$ \\
$\mathrm{V}_{\mathrm{dc}}$ Limit & $910 \mathrm{Vdc} ;$ & $800 \mathrm{Vdc} ;$ \\
$\mathrm{G}_{\mathrm{cdc}}(\mathrm{s})$ & $0.004+0.4 / \mathrm{s}$ & $0.0004+0.004 / \mathrm{s}$ \\
$\mathrm{G}_{\mathrm{cinst}}(\mathrm{s})$ & 1 & 0.1 \\
Instantaneous limit & $10 \mathrm{~A}$ peak & $10 \mathrm{~A}$ peak \\
\hline $\mathrm{G}_{\mathrm{dq}-}(\mathrm{s}) ;$ & $1+50 / \mathrm{s}$ & \\
$\mathrm{G}_{\mathrm{d}+}(\mathrm{s}) ;$ G $\mathrm{q}+(\mathrm{s}) ;$ & $1+50 / \mathrm{s}$ & \\
$\mathrm{G}_{\mathrm{sc} 0}(\mathrm{~s}) ;$ & $1+50 / \mathrm{s}$ & $2+200 / \mathrm{s}$ \\
\hline $\mathrm{G}_{\mathrm{c} 2 \omega}(\mathrm{s})$ & & $2+10,000 / \mathrm{s}$ \\
\hline Output voltage regulator & & \\
\hline
\end{tabular}

The compensators were designed using classical Bode plot methods. To improve the stability of the simulation $10 \mu \mathrm{F}$ capacitors with a $1 \Omega$ equivalent series resistance (ESR) are connected at the regulator input and load terminals to neutral.

The dynamic response of the UPFC-light regulator is explored in Fig. 7. The regulator is allowed to settle into steady state operation with a balanced 100A 0.95 power factor load. At $\mathrm{t}=0.4067 \mathrm{~s}$, the voltage zero crossing in " $\mathrm{b}$ " phase, a 95A solar generator commences operation. The solar current ramps up over two $20 \mathrm{~ms}$ cycles and reaches its full current at $\mathrm{t}=0.4467 \mathrm{~s}$. Fig. 7 shows the output voltages are constant and well regulated at 240.0 Vac. The consumer voltages show no variation as the solar generation enters the network. Prior to $\mathrm{t}=0.4067 \mathrm{~s}$ the voltage sequence magnitudes are:

- $\quad$ Output (Consumer side) $\mathrm{V}_{+}=240.0 ; \mathrm{V}_{-}=0.0 ; \mathrm{V}_{0}=0.0$;

- Input (Upstream) - $\mathrm{V}_{+}=223.7 ; \mathrm{V}_{-}=0.0 ; \mathrm{V}_{0}=0.0$.

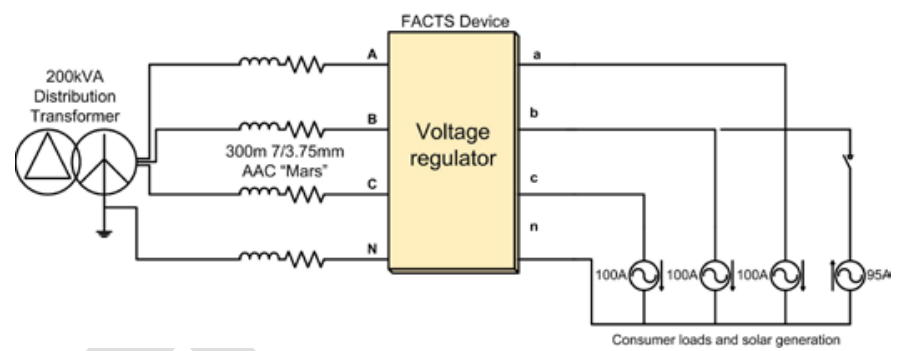

Fig. 6. FACTS Application at the end of a LV Feeder
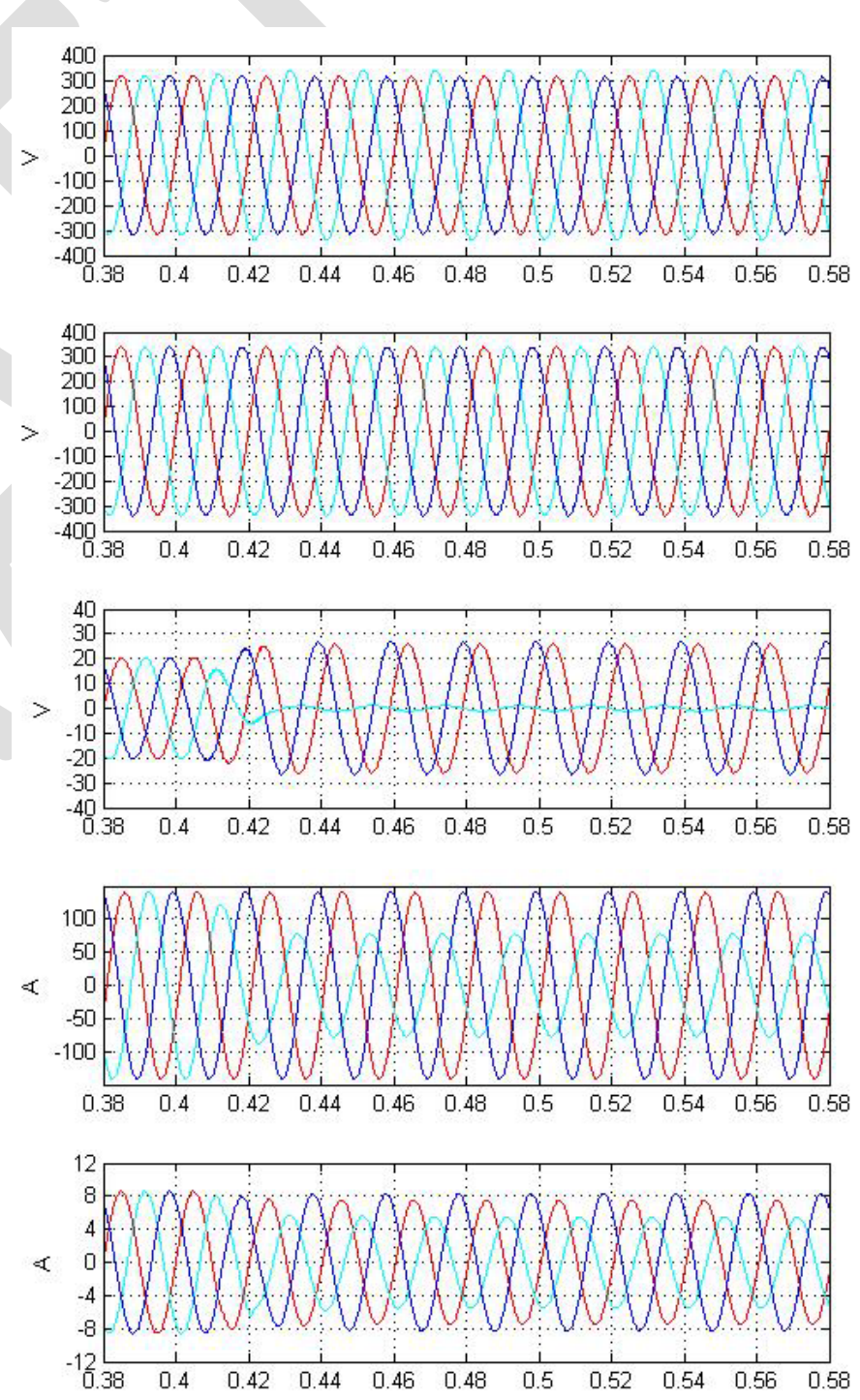

Fig. 7. UPFC-light results: Trace 1 - Voltages to $\mathrm{N}$ at Terminals A,B,C; Trace 2 - Voltages to $\mathrm{n}$ at Terminals a,b,c; Trace 3 - Injected Series Voltage; Trace 4 - Series Current; Trace 5 - Shunt Current. 
After the solar generation commences the phase voltage "b" (cyan) rises as the phase current reduces. Fig. 7 Trace 3 shows the response of the series injection converter. After $\mathrm{t}=0.4067 \mathrm{~s}$ the voltage injected in phase " $\mathrm{b}$ " (cyan) reduces over two cycles in response to the reduction in phase " $b$ " (cyan) current, seen in the lower trace. The voltages are:

- $\quad$ Output (Consumer side) $\mathrm{V}_{+}=240.0 ; \mathrm{V}_{-}=0.2 ; \mathrm{V}_{0}=0.6$;

- Input (Upstream) - $\mathrm{V}_{+}=228.0 ; \mathrm{V}_{-}=5.1 ; \mathrm{V}_{0}=20.0$;

The consumer side voltages remain very well regulated. The upstream negative and zero sequence voltages are very pronounced due to the load imbalance. A full dUPFC-heavy device would be able to rebalance the upstream currents and eliminate the negative and zero sequence voltages in this instance. Additionally, it would be able to make some improvements to the positive sequence voltage via reactive power control but in distribution systems the high $\mathrm{R} / \mathrm{X}$ ratio reduces the effectiveness of this approach.

Fig. 7 Trace 5 shows the response of the parallel converter in the dUPFC-light application. Prior to $\mathrm{t}=0.4067 \mathrm{~s}$ the input current is balanced and the regulator adds a balanced positive sequence voltage to control the voltages at terminals a,b,c. Figure 8 shows the real power requirement is $4.8 \mathrm{~kW}$. Once the solar generation starts the real power requirement drops and an oscillatory power requirement develops. The parallel converter draws a combination of positive and negative sequence currents to satisfy the real average power and $2 \omega$ oscillatory power requirement.

The positive sequence current feed-forward control system has a minimum $10 \mathrm{~ms}$ response time and the demand signal is shown as the third trace. The capacitor voltage feed-back regulation loop, the demand signal of which is shown as the fourth trace, starts to respond during the transient but is intended to correct any minor tracking errors in the feedforward system. In this case the instantaneous capacitor voltage limitation system does not respond as the upper voltage limit of $800 \mathrm{Vdc}$ was not reached. Fig. 9 shows the actions of the $2 \omega$ control loops. At $t=0.4067 \mathrm{~s}$ the oscillatory power requirement emerges and the $2 \omega$ control amplifiers begin to demand negative sequence sine and cosine currents as shown in the lower traces. The instantaneous powers of the series and parallel elements are seen in the top traces. These are quickly aligned and parallel converter is clearly forced to carry the $2 \omega$ power fluctuations and these do not appear on the DC bus.

Fig. 10 shows the response of a dSTATCOM to the same variable load. In this case the device will cancel the negative and zero sequence currents and compensate for any reactive power demand of the load. Fig. 10 Trace 4 shows that the resulting steady-state source current is well balanced. The device does not attempt to regulate the voltage as the $\mathrm{X} / \mathrm{R}$ ratio of 0.6 is relatively poor. This is a 75kVA dSTATCOM, with a phase leg rating of 150Ap designed for phase current balancing. It can provide $50 \mathrm{Ap}$ of zero sequence compensation and 100Ap or 70.7Arms of negative sequence compensation. The DC bus voltage working range is $\mathrm{V}_{\mathrm{L}}=600$ to $\mathrm{V}_{\mathrm{H}}=900 \mathrm{Vdc}$ and this requires a $690 \mu \mathrm{F}$ polypropylene $\mathrm{DC}$ bus capacitor.
Before the solar generation commmenced the steady state voltage was well balanced and 231Vrms. After the solar generation is established the system remaions well balanced and the load voltage is 234 Vrms. These are both less than the nominal 240Vrms system voltage due to the positive sequence voltage drops in the overhead lines.
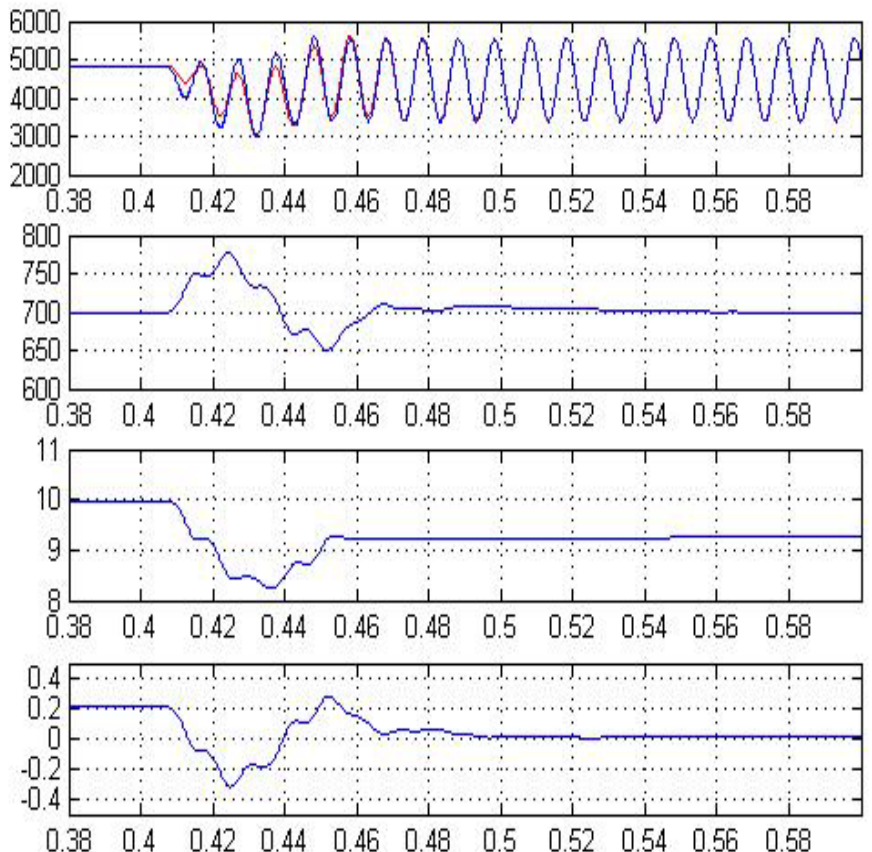

Fig. 8. dUPFC-light Top Traces Series Converter Power (Blue) and Shunt Converter Power (Red). Other Traces Top to Bottom: DC Bus Voltage; Positive Sequence Current Demand Feed Forward Signal; DC Bus Voltage Regulator Current Demand; Instantaneous Bus Voltage Current Demand.
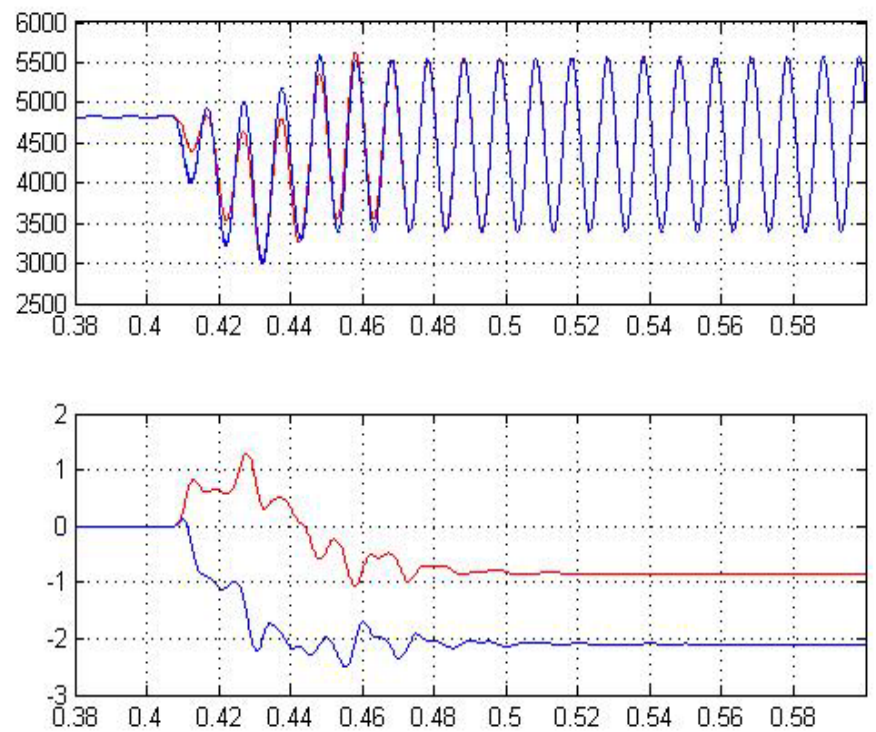

Fig. 9. Top Traces Series Converter Power (Blue) and Shunt Converter Power (Red). Lower Traces Current Demand Signals for Negative Sequence Cosine (Blue) and Sine (Red) Terms. 

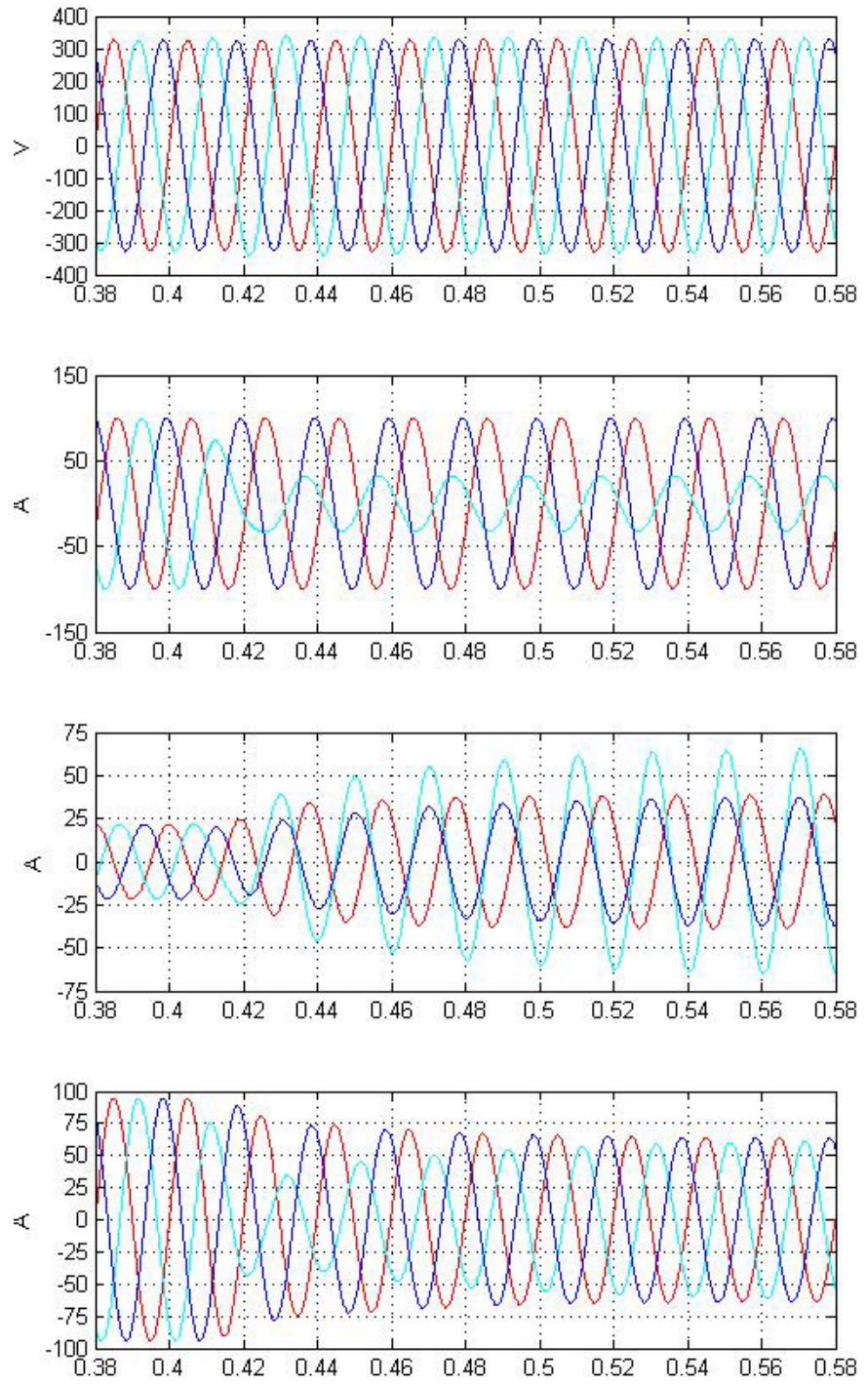

Fig. 10. dSTATCOM Results: Trace 1 - Terminal Voltage a,b,c, to n; Trace 2 - Load Current; Trace 3 - dSTACOM Current; Trace 4 - Source Current.

\section{CONCLUSIONS}

Distribution level FACTS devices such as dSTATCOMs and dUPFC type devices can be implemented in compact forms that are suitable for pole-top installations in low voltage networks. Low switching loss devices such as the higher voltage silicon-carbide mosfets allows lower loss converters to be produced. The removal of electrolytic capacitors and their replacement with non-polarized DC bus capacitors makes further improvements to the cost and reliability of dFACTS solutions. The major contribution of this paper is the demonstration of control methodologies that explicitly manage the DC bus voltage to allow successful operations with very low capacitances on the DC bus.

Distribution level STATCOMS and UPFC devices provide a practical means to improve power quality within the LV networks. Current balance can be directly addressed by
dSTATCOMs or UPFC-heavy devices. The capacity to rebalance networks provides a life extension benefit for distribution transformers that often experience significant load unbalance in residential feeders. Customer voltage regulation is most directly controlled by the UPFCs. All devices greatly increase the load carrying capacity of LV networks that are constrained by voltage drops and greatly improve the distributed PV generation hosting capability for those networks that are constrained by voltage rises. This paper has shown that high quality solutions can be readily implemented with sequence based controllers implemented in rotating reference frames.

\section{REFERENCES}

[1] J.M. Roney, "World power topped 100,000 megawatts in 2012", Earth Policy Institute , 31 July 2013, accessed 18 December 2013 at http://www.earth-policy.org/indicators/C47

[2] M.J.E. Alam, K.M. Muttaqi, D. Sutanto, “ A comprehensive assessment tool for solar PV impacts on low voltage three phase distribution networks”, IEEE International Conference on Developments in Renewable Energy Technology (ICDRET), 2012.

[3] F.Shahnia, R.Majumder, A.Ghosh., G.Ledwich and F.Zare, "Sensistivity of voltage unbalance in distribution networks with roof top PVs", IEEE PES General Meeting, Minneapolis 24-29 July 2010, pp1-8.

[4] Y. Li, P. Wolfs, "A hybrid model for residential loads in a distribution system with high PV penetration", IEEE Transactions on Power Systems, Vol 28, Issue 3, 2013, pp 3372-3379.

[5] X.Liu, A. Aichhorn, L. Liu, H. Li, "Coordinated control of distributed energy storage system with tap changer transformers for voltage rise mitigation under high photovoltaic penertation”, IEEE Transactions on Smart Grid, Vol 3, Issue 2, 2012, pp 897-906.

[6] N.Jayasekara, P. Wolfs, M.S. Masoum, “Optimal power management for LV distribution feeders with finely distributed PV and co-located storage”, IEEE PES General Meeting, Vancouver, 21-25 July, 2013.

[7] P. Wolfs, A. Maung Than Oo, "Improvements to LV distribution System PV penetration limits using a dSTATCOM with reduced DC bus capacitance”, IEEE PES General Meeting, Vancouver, 21-25 July, 2013.

[8] P. Wolfs, "A UPFC with reduced DC bus capacitance for LV distribution networks with high PV penetrations”, AUPEC 2012, Bali, 26-29th September 2012.

[9] A.I. Maswood, P.H. Raj, P.L.A. Vu, "Efficiency of silicon carbide based power inverters analytical results”, IEEE International Conference on Developments in Renewable Energy Technology (ICDRET), 2012.

[10] W. Lee, S.Sul, "DC-link voltage stabilisation for reduced DC-link capacitor inverter”, IEEE Transactions on Industry Application, Vol 50 Issue 1, 2014, pp404-414.

[11] J., M. Evangelista de Oliveira, M.F. Espindoa, T.G. de Siqueira , M.G. Villalva, E. Ruppert, “ Resonant (P+RES) controller applied to voltage source inverter with minimum DC-link capacitor”, IEEE Power Electronics Conference (COBEP) 2011, pp 409-414.

[12] Cornell Dubilier “Type 947D Ploypropylene High Energy Density DC Link Capacitors", viewed $8^{\text {th }}$ September 2012 at http://www.cde.com/catalogs/947D.pdf

[13] H.Fujita, Y. Wantanabbe and H. Akagi, "Transient analysis of a unified power flow controller and its application to design of the DC-link capacitor”, IEEE Transactions on Power Electronics, Vol 16, No 5, September 2001, pp 735-740.

[14] H. Akagi, E. Watanabe and M. Aredes, "Instantaneous power theory and applications to power conditioning”, John Wiley and Sons, 2007.

[15] T. Sezi, "Fast and accurate frequency measurement" IEEE PES General Meeting, Minneapolis 24-29 July 2010, pp1-7. 